\title{
Effects of culture media on detection of methicillin resistance in Staphylococcus aureus and coagulase negative staphylococci by disc diffusion methods
}

\author{
L M Milne, M R Crow, A G M Emptage, J B Selkon
}

\begin{abstract}
Aims-To test 10 culture media for their ability to detect resistance and sensitivity of staphylococci to methicillin by disc diffusion.

Methods-Fifty strains of Staphylococcus aureus and 135 strains of coagulase negative staphylococci were tested using Columbia, Diagnostic Sensitivity Test, Mueller Hinton, Sensitest and Isosensitest agars with and without 5\% added sodium chloride. Cultures were examined after 18 and 40 hours of incubation. The diameter of the zone and its characteristics were recorded and these media were assessed for their ability to produce clear, readable zones of inhibition. Changes in the variables which determined resistance were investigated. Results were analysed allowing a zone diameter reduction of $8 \mathrm{~mm}$ and $10 \mathrm{~mm}$ compared with the control in addition to the standard $6 \mathrm{~mm}$.
\end{abstract}

Results-Columbia agar with added sodium chloride supported the growth of all strains, detected the highest number of resistant strains, and was the easiest to read. Resistance was detected after 18 hours in most resistant strains, but some required 40 hours of incubation. There was poor agreement, however, on this medium (63-94\%) between disc diffusion and the reference MIC method for sensitive strains. Allowing a greater reduction in zone size resulted in more agreement with sensitive strains but with consequently lowered detection of resistant strains.

The other media showed some growth failures and more zones that were difficult to read. More resistance was detected when incubation was prolonged to $\mathbf{4 0}$ hours but this was consistently less than on Columbia agar with added salt. Conclusions-None of the media detected all of the resistant strains. Columbia agar with added salt was the most satisfactory medium in this respect, but it misidentified up to $37 \%$ of the sensitive strains as resistant. Methicillin susceptibility testing by disc diffusion testing is unreliable.

(F Clin Pathol 1993;46:394-397)
Resistance to methicillin in Staphylococcus aureus is heterogeneous and may be demonstrated in vitro using osmotic support in the medium, ${ }^{1-4}$ incubation at $30^{\circ} \mathrm{C}^{45}$ or $31^{\circ} \mathrm{C},{ }^{6}$ or prolonging the incubation to 48 hours. $^{247}$ Resistance to methicillin in coagulase negative staphylococci has also been shown to be heterogeneous ${ }^{49}$ and in vitro testing has entailed the use of osmotic support in the medium, ${ }^{410}$ incubation at $30^{\circ} \mathrm{C}^{48911}$ and prolonged incubation. ${ }^{4}$ The detection of methicillin resistance may be affected by the medium used for both $S$ aureus ${ }^{4-16}$ and coagulase negative staphylococci.412 To investigate further the effect of media, we examined staphylococci for susceptibility to methicillin by disc diffusion methods using 10 media.

\section{Methods}

Fifty strains of $S$ aureus and 135 strains of coagulase negative staphylococci were examined. In an earlier study these strains had been identified and designated as sensitive or resistant to methicillin by a minimum inhibitory concentration method. ${ }^{12}$ There were 31 strains of $S$ aureus and 63 strains of coagulase negative staphylococci resistant to methicillin by this reference testing method. ${ }^{12}$ $S$ aureus Oxford Public Health Laboratory strain number 13 was used as the control organism. This methicillin sensitive strain had a known minimum inhibitory concentration (MIC) to methicillin of $2 \mathrm{mg} / \mathrm{l}$. Columbia (CM331), Diagnostic Sensitivity Test (DST) (CM261), Mueller Hinton (CM337), Sensitest (CM409) and Isosensitest (CM471) agar bases were obtained from Oxoid Limited. The media were prepared following the manufacturers' instructions together with a duplicate set of media containing an additional $50 \mathrm{~g} / 1$ sodium chloride (salt). These 10 media were poured into $8.5 \mathrm{~cm}$ diameter Petri dishes in $20 \mathrm{ml}$ amounts. Antimicrobial discs (Oxoid) with a content of $10 \mu \mathrm{g}$ methicillin were used.

Staphylococci were subcultured from blood agar plates using standard techniques to obtain semi-confluent growth after incubation. Discs were applied to the agar surface of each medium using forceps. Plates containing added salt were incubated at $35^{\circ} \mathrm{C}$ and those 
Table 1 Number (\%) of $S$ aureus strains where disc and reference methods agreed

\begin{tabular}{|c|c|c|c|c|c|c|c|c|}
\hline & \multicolumn{4}{|c|}{ Methicillin resistant strains $n=31$} & \multicolumn{4}{|c|}{ Methicillin sensitive strains $n=19$} \\
\hline & \multicolumn{2}{|l|}{$18 h$} & \multicolumn{2}{|l|}{$40 h$} & \multicolumn{2}{|l|}{$18 h$} & \multicolumn{2}{|l|}{$40 h$} \\
\hline & $\boldsymbol{R}$ & $N / I G$ & $\boldsymbol{R}$ & $N / I G$ & $S$ & $N / I G$ & $S$ & $N / I G$ \\
\hline $\begin{array}{l}\text { Col + } \\
\text { Col } \\
\text { DST + } \\
\text { DST } \\
\text { MH + } \\
\text { MH } \\
\text { Sens + } \\
\text { Sens } \\
\text { Iso + } \\
\text { Iso }\end{array}$ & $\begin{array}{l}28(90) \\
28(90) \\
23(74) \\
24(77) \\
23(74) \\
24(77) \\
20(65) \\
24(77) \\
11(35) \\
18(58)\end{array}$ & $\begin{array}{l}0 \\
0 \\
0 \\
0 \\
0 \\
0 \\
0 \\
0 \\
0 \\
0\end{array}$ & $\begin{array}{l}30(97) \\
30(97) \\
25(81) \\
24(77) \\
27(87) \\
26(84) \\
23(74) \\
25(81) \\
22(71) \\
24(77)\end{array}$ & $\begin{array}{l}0 \\
0 \\
0 \\
0 \\
0 \\
0 \\
0 \\
0 \\
0 \\
0\end{array}$ & $\begin{array}{l}12(63) \\
18(95) \\
19(100) \\
19(100) \\
17(89) \\
19(100) \\
17(89) \\
19(100) \\
19(100) \\
19(100)\end{array}$ & $\begin{array}{l}0 \\
0 \\
0 \\
0 \\
0 \\
0 \\
0 \\
0 \\
0 \\
0\end{array}$ & $\begin{array}{l}12(63) \\
12(63) \\
19(100) \\
19(100) \\
12(63) \\
19(100) \\
18(95) \\
19(100) \\
18(95) \\
19(100)\end{array}$ & $\begin{array}{l}0 \\
0 \\
0 \\
0 \\
0 \\
0 \\
0 \\
0 \\
0 \\
0\end{array}$ \\
\hline
\end{tabular}

Col = Columbia agar; DST = Diagnostic Sensitivity Test agar; $\mathrm{MH}=$ Mueller Hinton agar; Sens = Sensitest agar; Iso = Isosensitest agar; $\mathbf{N}=$ No growth; IG = Insufficient growth .

$+=$ medium with $5 \%$ added sodium chloride

$R=$ resistant by disc diffusion and the reference method

$S=$ sensitive by disc diffusion and the reference method

without at $30^{\circ} \mathrm{C}$. The diameter of the zone of inhibition was measured after 18 hours and 40 hours of incubation. Strains were considered to be resistant to methicillin if the zone diameter was reduced by more than $6 \mathrm{~mm}$ compared with the diameter of the control organism tested under the same conditions or when colonies were seen within the zone of inhibition. Sensitive strains had a zone diameter greater than, equal to, or not more than 6 mm smaller than the diameter of the control organism. Assessments were also made of the zones on Columbia agars using criteria of 8 $\mathrm{mm}$ and $10 \mathrm{~mm}$ instead of $6 \mathrm{~mm}$. An organism which did not grow or grew very poorly under a particular test condition was recorded as no growth or insufficient growth. Strains which were resistant to methicillin by disc diffusion criteria on one or more tests but sensitive by the reference MIC method were considered separately as discrepant results.

The appearance of each zone of inhibition was also recorded after 18 hours and 40 hours of incubation on each of the 10 media. Five categories were used:

(A) A clear cut zone edge was produced. A strain was confidently recorded as sensitive or resistant to methicillin by the zone size criteria given above.

(B) An indistinct zone edge was produced so that recording the zone diameter was difficult.

(C) The zone of inhibition contained colonies which varied in size and could be difficult to see.

(D) No zone was produced as colonies grew up to the edge of the disc.

Table 2 Number (\%) of strains of coagulase negative staphylococci where disc and reference methods agreed

\begin{tabular}{|c|c|c|c|c|c|c|c|c|}
\hline & \multicolumn{4}{|c|}{ Methicillin resistant strains $n=63$} & \multicolumn{4}{|c|}{ Methicillin sensitive strains $n=72$} \\
\hline & \multicolumn{2}{|l|}{$18 h$} & \multicolumn{2}{|l|}{$40 h$} & \multicolumn{2}{|l|}{$18 h$} & \multicolumn{2}{|l|}{$40 h$} \\
\hline & $R$ & $N / I G$ & $R$ & $N / I G$ & $S$ & $N / I G$ & $S$ & $N / I G$ \\
\hline $\begin{array}{l}\text { Col + } \\
\text { Col } \\
\text { DST + } \\
\text { DST } \\
\text { MH + } \\
\text { MH } \\
\text { Sens + } \\
\text { Sens } \\
\text { Iso + } \\
\text { Iso }\end{array}$ & $\begin{array}{l}56(90) \\
41(66) \\
52(84) \\
39(63) \\
22(32) \\
34(50) \\
29(43) \\
26(42) \\
19(28) \\
25(37)\end{array}$ & $\begin{array}{l}0 \\
0 \\
0 \\
0 \\
3 \\
4 \\
4 \\
1 \\
5 \\
2\end{array}$ & $\begin{array}{l}57(92) \\
50(81) \\
56(90) \\
51(82) \\
31(50) \\
47(75) \\
48(77) \\
51(82) \\
48(77) \\
41(66)\end{array}$ & $\begin{array}{l}0 \\
0 \\
0 \\
0 \\
2 \\
1 \\
3 \\
1 \\
3 \\
1\end{array}$ & $\begin{array}{l}68(94) \\
67(93) \\
69(96) \\
70(97) \\
70(97) \\
67(93) \\
70(97) \\
68(94) \\
62(86) \\
69(96)\end{array}$ & $\begin{array}{l}0 \\
0 \\
0 \\
0 \\
2 \\
4 \\
0 \\
2 \\
9 \\
3\end{array}$ & $\begin{array}{l}67(93) \\
60(83) \\
71(99) \\
71(99) \\
69(96) \\
70(97) \\
69(96) \\
67(93) \\
69(96) \\
70(97)\end{array}$ & $\begin{array}{l}0 \\
0 \\
0 \\
0 \\
2 \\
1 \\
1 \\
2 \\
3 \\
1\end{array}$ \\
\hline
\end{tabular}

*Staphylococcus epidermidis $\mathrm{n}=93 ; \mathrm{S}$ haemolyticus $\mathrm{n}=19 ; S$ simulans $\mathrm{n}=11 ; S$ warneri $\mathrm{n}=6 ; S$ capitis $\mathrm{n}=3 ; S$ xylosus $\mathrm{n}=2 ; S$ hominis $\mathrm{n}=1$
(E) Insufficient or no growth occurred; therefore a reading was not possible.

\section{Results}

Table 1 sets out the results for $S$ aureus separately for the strains which were defined as methicillin resistant or sensitive by the reference method. Satisfactory growth was obtained for all strains on all media. Columbia agar alone or with added salt detected $28(90 \%)$ of the 31 resistant strains after 18 hours of incubation and $30(97 \%)$ after 40 hours of incubation. All other media were less satisfactory in this respect. Mueller Hinton agar with added salt was in second place, detecting $74 \%$ at 18 hours and $87 \%$ at 40 hours. DST agar was third, detecting $77 \%$ at both 18 and 40 hours. The 19 methicillin sensitive strains were all detected as sensitive after $\mathbf{4 0}$ hours on DST agar with or without added salt and on Mueller Hinton, Sensitest, and Isosensitest agars without added salt. Columbia agars, however, with or without added salt, were only able to detect $63 \%$ of the strains at $\mathbf{4 0}$ hours.

Thus the media which correctly detected most $(97 \%)$ of the resistant strains-that is Columbia agars with or without added saltwere unable to detect more than $63 \%$ of the sensitive strains after 40 hours. Conversely, the media which correctly detected all the sensitive strains were, individually, unable to detect more than $84 \%$ of the resistant strains.

Table 2 presents in a similar form the results obtained with coagulase negative staphylococci. Only Columbia agars and DST agar both with or without added salt yielded satisfactory growth of all the 135 strains. The number of strains which failed to achieve adequate growth, however, was low (1\%-7\%). Columbia agars with added salt detected $90 \%$ of the 63 methicillin resistant strains at 18 hours and $92 \%$ at 40 hours. DST agar plus salt was second, detecting $84 \%$ at 18 hours and $90 \%$ at 40 hours. All the other media performed considerably worse in this respect, detecting only $82 \%$ to $66 \%$ at 40 hours.

Nearly all the media correctly detected over $90 \%$ of the 72 methicillin sensitive strains. DST agar with or without salt was best, detecting $96-97 \%$ at 18 hours and $99 \%$ at 40 hours. Mueller Hinton agar was second, detecting $93 \%$ at 18 hours and $97 \%$ at 40 hours. Columbia agars with added salt, the best medium for the detection of resistant strains, correctly detected only $94 \%$ of the sensitive strains at 18 hours and $93 \%$ at 40 hours.

Methicillin sensitive strains of staphylococci, which were resistant on disc diffusion testing, were further examined to determine whether a different definition of resistance would reduce these discrepant results. Nine strains of $S$ aureus and 18 strains of coagulase negative staphylococci produced a total of 80 of these discrepant results. All the base agars were involved; Columbia (48 discrepant results), Mueller Hinton (12), Sensitest (8), DST (7), and Isosensitest (5). The results fell into two groups, with three strains repre- 
Table 3 Number (\%) of strains where disc and reference methods agreed using three different criteria on Columbia agars with and without added salt

\begin{tabular}{|c|c|c|c|c|c|c|c|c|c|}
\hline \multirow{3}{*}{$\begin{array}{l}\text { Zone } \\
\text { reduction }\end{array}$} & & \multicolumn{4}{|l|}{$S$ aureus } & \multicolumn{4}{|c|}{ Coagulase negative staphylococci } \\
\hline & & \multicolumn{2}{|c|}{$\begin{array}{l}\text { Methicillin } \\
\text { resistant } n=31\end{array}$} & \multicolumn{2}{|c|}{$\begin{array}{l}\text { Methicillin } \\
\text { sensitive } n=19\end{array}$} & \multicolumn{2}{|c|}{$\begin{array}{l}\text { Methicillin } \\
\text { resistant } n=63\end{array}$} & \multicolumn{2}{|c|}{$\begin{array}{l}\text { Methicillin } \\
\text { sensitive } n=72\end{array}$} \\
\hline & & $18 h$ & $40 h$ & $18 h$ & $40 h$ & $18 h$ & $40 h$ & $18 h$ & $40 h$ \\
\hline \multirow[t]{2}{*}{$6 \mathrm{~mm}$} & $\mathrm{Col}+$ & $28(90)$ & $30(97)$ & $12(63)$ & $12(63)$ & $56(90)$ & $57(92)$ & $68(94)$ & $67(93)$ \\
\hline & $\mathrm{Col}$ & $28(90)$ & $30(97)$ & $18(95)$ & $12(63)$ & $41(66)$ & $50(81)$ & $67(93)$ & $60(83)$ \\
\hline \multirow[t]{2}{*}{$8 \mathrm{~mm}$} & $\mathrm{Col}+$ & $26(84)$ & $27(87)$ & $18(95)$ & $15(79)$ & $52(83)$ & $54(84)$ & $72(100)$ & $71(99)$ \\
\hline & $\mathrm{Col}$ & $24(77)$ & $30(97)$ & $19(100)$ & $14(74)$ & $36(57)$ & $47(75)$ & $71(99)$ & $67(93)$ \\
\hline \multirow[t]{2}{*}{$10 \mathrm{~mm}$} & $\mathrm{Col}+$ & $24(77)$ & $25(81)$ & $19(100)$ & $19(100)$ & $50(79)$ & $50(79)$ & $72(100)$ & $71(99)$ \\
\hline & Col & $24(77)$ & $28(90)$ & $19(100)$ & $18(95)$ & $34(54)$ & $43(68)$ & $71(99)$ & $71(99)$ \\
\hline
\end{tabular}

sented in both. The first group consisted of 25 discrepant results from eight strains which had colonies within the zone of inhibition or no zone. This was not related to the type of mediuin and duration of incubation. In the second group there were 55 discrepant results from 22 strains with a reduction in zone size compared with the control, tested on the same medium, of between $6 \cdot 1-10 \cdot 1 \mathrm{~mm}$. As 48 of the 80 discrepant results occurred on Columbia agars with or without added salt, a further analysis of results from this medium was undertaken.

Table 3 records the results for Columbia agars, with and without added salt, allowing a zone size reduction of more than $8 \mathrm{~mm}$ or more than $10 \mathrm{~mm}$, compared with the diameter of the control, as well as the $6 \mathrm{~mm}$ previously used. More of the resistant strains of both $S$ aureus and coagulase negative staphylococci were detected after both 18 hours and 40 hours if a $6 \mathrm{~mm}$ reduction was the cutoff used, rather than $8 \mathrm{~mm}$ or $10 \mathrm{~mm}$. For $S$ aureus on Columbia agars with added salt at 40 hours, $97 \%$ of the resistant strains were detected compared with $87 \%$ and $81 \%$, respectively. The detection of methicillin sensitive strains of $S$ aureus and coagulase negative staphylococci, however, improved if 8 $\mathrm{mm}$ or $10 \mathrm{~mm}$ was used as the cutoff, rather than $6 \mathrm{~mm}$. For $S$ aureus at 40 hours, $79 \%$ and $100 \%$, respectively, were detected, compared with only $63 \%$ using the $6 \mathrm{~mm}$ diameter definition.

The figure shows the number of recordings

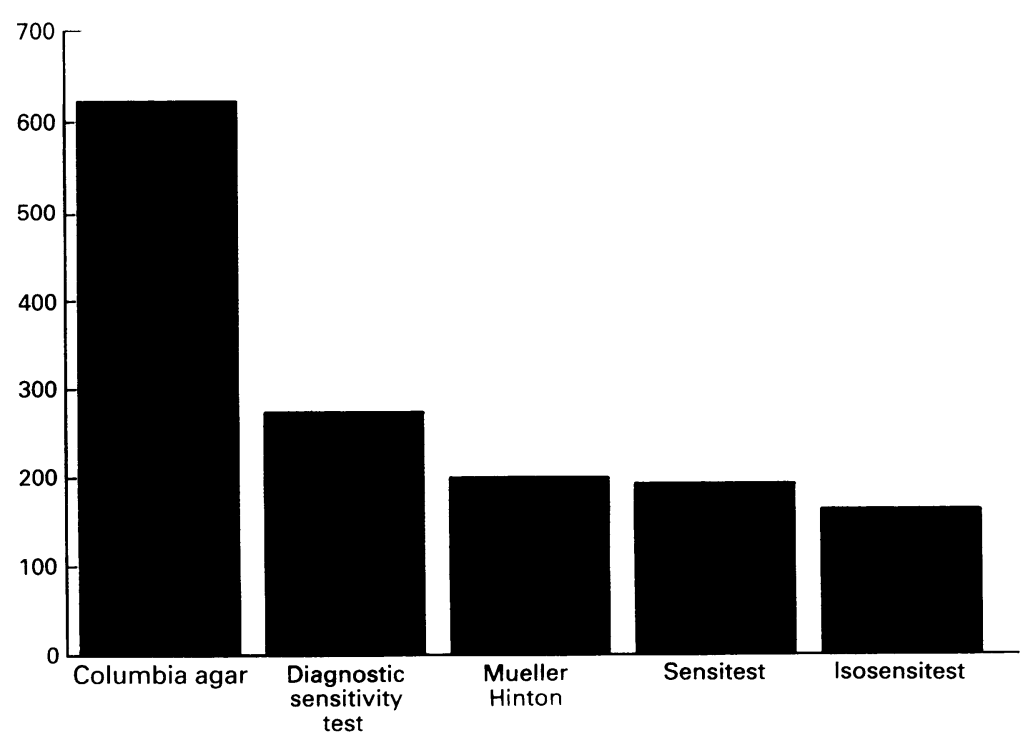

Number of results which were easy to interpret (categories $A$ and $D$ ) on each agar base. in categories $\mathrm{A}$ and $\mathrm{D}$, for both $S$ aureus and coagulase negative staphylococci (with the 18 hour and 40 hour results combined) for all the agar bases with and without added salt. These categories were easy to read and interpret by our criteria as clearly sensitive or resistant. Disc diffusion results for all staphylococci were easiest to read on Columbia agars with or without added salt. All 63 of the methicillin resistant strains of coagulase negative staphylococci were easy to read and interpret on these two media after 18 hours' incubation.

\section{Discussion}

Various disc diffusion techniques have been used to detect methicillin resistance in $S$ aureus $^{2-7101113-18}$ and coagulase negative staphococci ${ }^{48101117-20}$ on DST, ${ }^{1318}$ Mueller Hinton, ${ }^{1517}$ Sensitest ${ }^{13}$ and Isosensitest $^{1415}$ agars:

Along with other workers 281013161820 we have found a lack of agreement between disc diffusion and agar incorporation MIC results. We have shown that the expression of resistance is greatly influenced by test conditions as others have found. ${ }^{4}$ We agree that prolonging the incubation to 40 hours detects more of the resistant strains.?

Columbia agars with and without added salt were the best media for detecting methicillin resistance in $S$ aureus in our study. But $37 \%$ of the sensitive strains also seemed to be resistant. In contrast, on DST agar on which all the sensitive strains were correctly identified, only $77 \%$ of the resistant strains were detected after 18 hours and 40 hours. This latter finding contradicts the finding of $97 \%$ detection of resistant strains in another study. ${ }^{13}$

All other media we studied failed to detect $10 \%$ or more of the resistant strains, a finding in agreement with some, ${ }^{14,16}$ but not with others $^{13}$ where all resistant strains were correctly identified. All the sensitive strains were correctly identified on DST, Mueller Hinton, Sensitest and Isosensitest agars as in previous reports. ${ }^{13.15}$ Others, however, have shown that sensitive strains have been designated as resistant. ${ }^{16}$

Coagulase negative staphylococci grew better on Columbia and DST agars with or without added salt, than on Mueller Hinton, Sensitest, or Isosensitest agar with or without added salt. This improved growth on Columbia agars were also reported for studies of methicillin resistance when MIC methods ${ }^{12} 20$ were used. 
None of the media detected all the resistant strains. Columbia agar with added salt was best, as has been reported in MIC studies, ${ }^{12}$ detecting $90 \%$ after 18 hours and $92 \%$ after 40 hours. On Mueller Hinton agar, 50\% of resistant strains were identified after 18 hours and $75 \%$ after 40 hours. In contrast, all resistant strains were identified on Mueller Hinton agar in one study, ${ }^{19}$ although some were not in another. ${ }^{20}$ Methicillin sensitive strains of coagulase negative staphylococci were more reliably identified on all the media, compared with methicillin resistant strains, and all media gave similar results.

For the disc diffusion method there is no uniformity of opinion as to how to define resistance. We determined our disc diffusion result by comparing the diameter of inhibition with that of a control organism, as others have done. ${ }^{4}$ Using this definition of more than a $6 \mathrm{~mm}$ reduction of the zone of inhibition compared with the control, we found that strains sensitive by the reference MIC method were resistant on the disc diffusion test, a finding that has been reported before. ${ }^{16}$ Most of these discrepant results were obtained on Columbia agars with or without added salt. Most of these strains, which were incorrectly classified as resistant, had a zone size that was reduced by more than $6 \mathrm{~mm}$ compared with the diameter of the control organism, but not because colonies were present within the zone of inhibition or because growth had occurred up to the edge of the disc. The detection of sensitive strains on Columbia agars with or without added salt was improved and these discrepant results were decreased or eliminated if a sensitive strain was defined as producing a zone diameter of inhibition not less than either $8 \mathrm{~mm}$ or $10 \mathrm{~mm}$ smaller than the diameter of the control organism, instead of $6 \mathrm{~mm}$. Thus for methicillin sensitive strains of $S$ aureus on Columbia agars with added salt after 40 hours of incubation, $63 \%$ were correctly identified if $6 \mathrm{~mm}$ was used, compared with $79 \%$ if $8 \mathrm{~mm}$ was used and $100 \%$ if $10 \mathrm{~mm}$ was used. If $8 \mathrm{~mm}$ or $10 \mathrm{~mm}$ were adopted, however, the detection of resistant strains was considerably less satisfactory. Thus for methicillin resistant strains of $S$ aureus on Columbia agars with added salt after 40 hours of incubation, $97 \%$ were correctly identified if $6 \mathrm{~mm}$ was used, compared with $87 \%$ using $8 \mathrm{~mm}$ and $81 \%$ using $10 \mathrm{~mm}$. Other studies have also described difficulties in establishing adequate definitions of sensitivity or resistance for the disc diffusion method..$^{814-16}$

The results of the disc diffusion tests were easiest to read when Columbia agars were used. Mueller Hinton agar has been recommended in national guidelines for use in testing the susceptibility of staphylococci to methicillin $^{17}$ and Isosensitest has also been used, ${ }^{4}$ but the results we obtained on these media were more difficult to interpret. Growth appearances seen in this study and reported by others include hazy ${ }^{45}$ or colony growth within the zone of inhibition, ${ }^{2471520}$ especially after prolonged incubation, ${ }^{7}$ zone sizes affected by the media used ${ }^{13}$ and resis- tant strains producing large zones of inhibition. ${ }^{15}$ These appearances were due to the heterogeneous nature of resistance ${ }^{78}$ and we agree with others ${ }^{41516}$ that there are practical difficulties in reading and interpreting results.

In summary, this study has shown that for testing staphylococci for methicillin susceptibility by disc diffusion, Columbia agars with or without added salt were better in terms of detecting resistance compared with the other media studied. On Columbia agars with or without added salt, all strains grew adequately and the results were clearer to read. But the extent of incorrect "resistant" results obtained with methicillin sensitive strains was unacceptable. Although this designation varied according to the definition of resistance adopted, for the definition of which detected most of the resistant strains it was unsatisfactory. We therefore conclude that methicillin susceptibility testing by disc diffusion is unreliable. It can nevertheless be used to screen $S$ aureus strains provided that incubation is extended to 40 hours and that all "resistant strains" are subsequently confirmed as resistant by an agar incorporation break-point method. 1 Barber M. Naturally occurring methicillin-resistant

2 Hewitt JH, Coe AW, Parker MT. The detection of methicillin resistance in Staphylococcus aureus. $f \mathrm{Med}$ Microbiol 1969;2:443-56.

3 Churcher GM. A screening test for the detection of methicillin-resistant staphylococci. F Clin Pathol 1968;21: 213-7.

4 Working Party of the British Society for Antimicrobial Chemotherapy. A guide to sensitivity testing. $f$ Antimicrobiol Chemother 1991;27:Suppl D.

5 Cheng AF, French GL. Methicillin-resistant Staphylococcus aureus bacteraemia in Hong Kong. $\mathcal{f}$ Hosp Infect Eur 1988;12:91-101.

6 Annear DI. The effect of temperature on resistance of Staphylococcus aureus to methicillin and some other antibiotics. Med $\mathcal{F}$ Aust 1968;1:444-6.

7 Sutherland R, Rolinson GN. Characteristics of methicillin-resistant staphylococci. $f$ Bacteriol 1964;87: 887-99.

8 Richardson JF, Marples RR. Differences in antibiotic susceptibility between Staphylococcus epidermidis and Staphylococcus saprophyticus. 7 Antimicrobiol Chemother 1980;6:499-510.

9 Hamilton-Miller JM, Iliffe A. Antibiotic resistance in coagulase-negative staphylococci. $\mathcal{F}$ Med Microbiol 1985; 19:217-26.

10 Coudron PE, Jones DL, Dalton HP, Archer GL. Evaluation of laboratory tests for detection of methiEvaluation of laboratory tests for detection of methi-
cillin-resistant Staphylococcus aureus and Staphylococcus epidermidis. $\mathcal{F}$ Clin Microbiol 1986;24:764-9.

11 McAllister TA, Mocan H, Murphy AV, Beattie TJ Antibiotic susceptibility of staphylococci from CAPD peritonitis in children. $\mathcal{F}$ Antimicrobiol Chemother 1987 19:95-100.

12 Milne LM, Curtis GDW, Crow M, Kraak WAG, Selkon JB. Comparison of culture media for detecting methicillin resistance in Staphylococcus aureus and coagulase negative staphylococci. F Clin Pathol 1987;40:1178-81.

13 Brown DFJ, Kothari D. The reliability of methicillin sensitivity tests on four culture media. F Clin Pathol 1974; 27:420-6.

14 Brown DFJ, Yates VS. Methicillin susceptibility testing of Staphylococcus aureus on media containing five percent Staphylococcus aureus on media containing five percer
sodium chloride. Eur $₹$ Clin Microbiol 1986;5:726-7.

15 French GL, Ling J, Hui Y, Oo HKT. Determination of methicillin-resistance in Staphylococcus aureus by agar dilution and disc diffusion methods. If Antimicrobio Chemother 1987;20:599-608.

16 Mouton RP, Mulders SLTh, de Knijff J, Hermans J. Comparison of test systems for recognition of methicillin resistance in Staphylococcus aureus. Eur $\mathcal{f}$ Clin Microbiol 1989;8:968-73.

17 National Committee for Clinical Laboratory Standards Approved Standard. Performance standards for antimicro bial disk susceptibility tests-fourth edition. M2-A4. Villanova, Philadelphia: NCCLS. 1990.

18 Jolly J, Goldberg M. Methicillin resistance in staphylococci: an evaluation of conditions for detection. Med Lab Sci 1989;46:2-5.

19 Libert JM, Colas des Francs D. Sensibilité aux céphalosporines de staphylocoques coagulase négatifs méticilline résistants. Pathol Biol 1985;33:831-5.

20 Hedin G, Hambraeus A. Screening tests for the detection of methicillin resistance in Staphylococcus epidermidis. of methicillin resistance in Staphylococcus 